\title{
Recreational Activities for the Physical Challenged In Nigeria.
}

\author{
Alu Timothy Eliya And Gabi Sunday Tsibi. \\ Nasarawa State Polytechnic, Department Of General Studies \\ P.M.B 109, Lafia-Nigeria.
}

\begin{abstract}
The need for bodily activities is equally vital for the child with physical disability. Individuals with prolonged periods in hospital for surgical treatment, hereditary or genetic ailments, over-protection or perhaps, the frustrations and even pain of ill coordinated degenerative disease may however, have deprived them of the fun and satisfaction enjoyed their colleagues who are physically fit. The physically challenged are defective sight, totally crippled or blind hearing disorders or completely deaf while others have speech defects, lowered vitality, limited mental processes, emotional disturbance and some exceptionality. All the physical challenges persons need to engage sufficient varieties of physical activities, exercises or sports of daily living which values are immeasurable for physical, psychological, social and emotional adjustment. This paper therefore highlighted the various recreational activities for the physical challenged and possible benefits that accrue for their healthful living.
\end{abstract}

Keyword: Recreational activities, Physical disability, Emotional disturbance and healthy living.

\section{Introduction}

An individual's health is paramount for a healthful living. Agwubike (1986) opined that Nigeria have not made health maintenance a number one priority unlike other developed nations. A reflection of this is evidenced in the fact that all activities that form the pattern of one's life are taken for granted until some form of dysfunction intervenes.

During the period of growth, it is essential that children have frequent opportunities for body activity. For them and other social animals, free and active movement is as necessary for health and development as are fresh air, sunshine, nutritive foods and ample sleep. It is indeed fortunate that children delight in these "free and active movements" as a necessity for health and growth as well as to attain full physical, psychological and social development. Evidence of research has recorded the important of a child's exploration of his environment and his ability to adapt and modify his behaviour patterns and responses through sensory and motor skills. Their observations have shown that "the child displays various skills towards mastery of his environment and tends to adopt a style of behaviour and response which provides a technique for achieving mastery".

The wriggling, kicking, and exploratory crawling of the baby, which clearly give him great joy, satisfaction and pleasure prepare the way for the increasing bodily skills of his childhood years and later more sophisticated physical activities. The changing pattern of physical education curriculum, sports and game in recent years reflects the educationalists' awareness of these basic physical, psychological and social needs of the child towards developing the spirit of sportsmanship, fun and adventure. With the new emphasis on the building of the child's resources in movement exploration and life-long skills acquisition for living marked a significant contribution to educational development of the child from childhood to adulthood.

The need for bodily activity through interaction is equally vital for the physically challenged child. Prolonged period in hospital for surgical and other genetic disease treatment, the necessary restrictions of his movements, over-protection, or perhaps, the frustration and even pains of his ill-coordinated movements may, however have deprive him of the fun and satisfaction enjoyed by his opposite sex who are physically fit in all ramifications. The department of Education and Science (1971) revealed a high proportion of handicapped children to some extent due to poor awareness of body image and distortions in the visuo-motor fields. This distortion may be linked directly with disability of any kind especially when there are some degree of brain damage resulting to poor sensory and motor experiences at the appropriate stages of development.

Teachers and other scholars engaged in special education have recognized the importance of physical education, sports and games to the all round development of the physically challenged child during their recreational, leisure or free time. They further stressed that fun; satisfaction and motivation are derived from mass participation in recreational activities. This explains why Adima (1988) stated in one of the objectives of special education that, the handicapped child be assisted to become participant and spectator in various physical activities during their leisure hours, to give responsible direction to his healthful living and appropriate lifestyle.

The National policy on Education (1977) and (2004) also affirmed among other objectives under the philosophy of Nigerian Education that adequate provision of sporting facilities, equipment and supplies be provided and made accessible to all category of pupils at all levels of education for its citizens irrespective of one's fitness status or disabilities. This worth affirmation are a challenge in the education of the physically 
challenged child. Though the handicapped child is deficient in some of the very tools with which to attain the Nigerian philosophy of Education, as many are defective in sight or totally blind. Other shave mild hearing impairment or completely deaf, some have speech defects, crippled, lowered vitality, limited mental processes, emotional disturbances and other exceptionalities. The challenge readily becomes clear that these categories of children must be provided with recreational activities, games and sports that will give them a sense of belonging and an all round development of the body.

\section{Recreation Defined}

Recreation has different meanings attributed to it relating to a great variety of activities and situations. One man's recreation may be another man's work for living. Even with the same individual, an activity that affords recreation at one time or under certain conditions does not always yield the satisfaction which makes it recreation. Though some activities are enjoyed through life, yet others varies as there are changes in individual's age, interest, physical ability, intellectual capacity and desires.

Butcher (1975) characterized recreation as being a leisure time activity, an enjoyable activity, constructive in nature or whole some, non-survival in nature, and voluntary. This explains why Agwubike (1986) said, recreation can be experienced by a person while alone, or in a midst of a few people, or in a large group According to Gray and Greben (1975), recreation is conceptualized as "an emotional condition within an individual human being that flows from a feeling of well-being and self-satisfaction; characterized by feeling of mastery, achievements, exhilaration, acceptance, success, personal worth and pleasure" Omoruan (1979) sees recreation, as an activity, voluntarily engaged in during leisure time or one's free time without compulsion of any types or other than an urge from within and the resultant personal satisfaction.

Dodbey as reported by Olowoyo (1986) agreed and asserts that recreation is an activity done in opposition to work which refresh and restore the individuals' emotional disturbance. This is why Butler (1967) confirment that recreation contributes to human happiness. Happiness, according to the author, is a by-product of a balance life. This is also confirmed by Butcher (1975) when he summaries recreation, as that field of endeavour concerned with those social acceptable and worthwhile activities in which a person voluntarily participate during leisure hours and through which he/she may better develop physically, mentally, socially and emotionally.

From the various concepts expressed, one is able to deduce that recreation is a change of activity different from one daily routine for a healthful living.

\section{Who Are The Physically Challenged Or Handicapped?}

The terms "physically challenged," Handicapped, Impaired, and Disabled are often used interchallengeably and synonymously by both professional and lay people. Until recent years any One with an abnormal condition or who deviated from the majority in any way was considered handicapped or physically challenged.

There are people whose participation in physical activity, exercise or sport is limited because of some physical or mental impairment. These people are exceptions to general rule, but they still posses potential capabilities and aspirations for participation and development.

According to Daniel (1965), children are classed exceptional when they are in mental, physical, social, emotional or behavioral characteristic. Cruickshank (1971) however does not distinct categories of exceptional but covered children with physical disabilities, speech defects, vision or sight impaired, orthopedic impairments, brain injuries, auditory or hearing difficulties, chronic medical problems, mental retardation giftedness, and emotional or psychological disturbances.

For purposes of clarification, impaired individuals have identifiable organic or functional conditions. Some part of the body is actually missing, a portion of an anatomical structure is gone, or more parts of the body do not function properly or adequately. The condition may be permanent, as in the case of amputation, congenital birth defect, vertebral or cerebral palsy, brain damage, etc. it may be temporary functional speech defects, some learning skills disabilities, various emotional problems, certain social maladjustments, or specific movement or locomotive deficiencies.

Disabled individuals are physically challenged because their impairment are limited or restricted in executing some skills when doing specific jobs or tasks, or performing certain physical exercises or sporting activities.

They are described handicapped or physically challenged individuals because their impairment, defect or disability are adversely affected psychologically, emotionally, or Socially. Physically challenged persons reflect an attitude of pity. Some individuals with disabilities and impairments are handicapped mildly while others are severed. Those with severe impairments or disabilities adjust extremely well to their conditions and live happy lives. In their eyes or mind, they are not handicapped or disabled, even though society continues to label them physically challenged persons (Daniel, 1965). 
From the foregoing, those considered physically challenged are individual with one or multiple forms of impairments which restricts their participation in physical activities or sports directly or indirectly like their able physically fit individuals.

\section{Recreational Activities For The Physically Challenged}

The place of recreation as a social force for a healthy-being in modern life is well established. The physically challenged both need and can benefit from recreation, like anyone else. However, one problem is to increase the recreation services or centres available to them. Another is to get them to become more receptive to those recreational experience that can enrich their living for life. Too many of the handicapped feel that most form of active recreation are not meant for them.

Daniel (1965) Observed that the disabled needs recreational form of expression that are within his/her capacity. Agwubike (1986) confirmed this statement when he said recreational activity for one person may be a drudgery for another. Some physical education activities or sport are obviously unsuitable for children with particular disability. In this respect, he/she is just like his/her fellow citizens. But what can they do? And where will they go? A good family or community should be able to help the child in finding an answer to these questions through coordinated efforts of the home, school, church, public and private agencies. Some of these efforts might include elimination of architectural barriers which often prohibit their participation.

The kind of recreation the physically challenged can engage in is conditioned by the person himself and his type of impairment. This is why Agwubike (1986) asserted that, for activity to become there Peutic or instrumental in producing change in a direction from dysfunction toward function, it becomes necessary to arouse and harness the individual's will to learn. The problem of matching and selection, possibilities for success, safety, naturalness, and interest must be considered. There should be a balance between directly participating and being a spectator in many recreational activities. In the area of game and sports, those of the non-contact or non-combat type with low requirements in speed, strength, agility and endurance (achieving performance related physical fitness status or components) offer the best chance for safe and successful participation for those with physical impairments.

According to Department of Education and Science, (DES) London (1971), observed that boys with haemophilia and a history of severe bleeding episodes, or with haemarthroses, should not be submitted to the risk of trauma and permanent handicap by taking part in any unnecessary severe physical activity or sports of any kind. Any activity is unsuitable it, in any way, it aggravates the disability. However, activities such as archery and modified forms of athletics (track or field events), which may be practical from a wheel chair such as Javelin, Discus and Short Put throwing, are very valuable for strengthening the muscles because of lower limb paralysis (Hyman, 1974).

The mentally impaired is not exception or limited to these activities, but he/she should be guided into activities in which he can be successful. These may include both contact and non-contact sports that require speed and strength, and, or for some endurance and coordination. To support this claim, Agwubike (1986) confirmed that people suffering from mental or psychological disorders were found to react to the stimulus play. He went further to attest that music was used with success as a therapeutic agent in institutions for mental patients. The author further quoted king David's use of harp (Iyre) to relieve Saul from the ill-effects of evil spirits as a recreational activity (The Holy Bible, I Samuel 16:14-23). This explains why William (1976) stated that, recreation has not only played an important role in treatment programme of many mental illness but it has been a considerable factor in enabling former patients to remain well.

Swimming is one of the longest established and most valuable activities for the physically challenged or handicapped. The value of swimming for educational, recreational and survival purpose is as relevant for physical handicapped as for normal children. Children with congenital limb deformities demonstrate their versatility in water, either using different swimming strokes (back stroke or front craw/and butterfly stroke) with their fronts or backs using their feet, or with variety of inflatable "aids". Children with spinal cord problems, difficulties in passing urine or faeces may swim, both for therapy and enjoyment, if suitable precautions are taken. The intention here, however, is not to discuss each handicap with appropriate recreational activity but to show the real need for such recreation activities for the physically challenged.

Other recreational activities necessary for the handicapped are canoeing, movement education: all disable have urge to move, to explore their environment, to scramble over and under, to negotiate obstacles of all kinds, etc. Games such as volleyball, soccer, badminton, table-tennis, basketball, handball, billiards, hockey, etc with few modifications could be played from wheel chair and modified equipment (Faye, 1974). Children derived a lot of fun from these games. In some instances, very simplified games and activities could be ingeniously devised. These games could be organized in pairs or small groups.

Athletics play an important part in body development and can also serve as a therapeutic measure. Events such as Javelin, Discus throwing and Putting the short (Shot put) can be included. According to Daniel (1965), Hobbies and enterprise that may serve as recreational activities include gardening, woodworking, music, 
fly-tying, photography, painting and reading. He further asserted that many quiet games or leisure time activities such as playing cards, checkers, chess, darts, scramble, dominoes, etc are important. Also Okunrotifa (1980) listed recreational activities for the physically challenged to include painting, drawing, climbing, singing, swimming, hopping, story-telling and creative rhythm. All these activities are channeled towards development of physical/, mental, social, emotional and educational activities.

Indigenous activities such as Alopipa (Yoruba), Farauta (Hausa), Oyi-agen (Eggon), Iche (Idoma), Ntugari (Igbo) are recreational and also valuable to one's social health (Oyirinde, 1986). These indigenous activities when engaged in teaches obedience, co-operation, respect for others, good leaderdship and followership. Udenyi (1986) recommended some other activities for the handicapped which include motor skills like squat thrust and vertical jump for mentally retarded. In addition, Trampoline task, gymnastic exercises and ball skills are also recommended to enhance the neuro muscularly impaired deaf individual's physical fitness status, ensure his perfect state of mind and relieve him of tension, fear and frustration characterized in his life (Adams, etal. 1975).

Faith (1978) and Dunn (1980) further asserts that physical fitness programmes such as jogging, running, skipping, hopping, leaping, kicking, lifting, and more will enhance the physically challenged's muscular strength and endurance, cardio-respiratory endurance, flexibility and body co-ordination. It also release the handicapper's tension and aid their social development, improve physical coordination, freedom of movement and aggression elimination. Out of doors recreation offers excellent opportunities in camping, picnics, cycling, boating, fishing and touring expedition (Nixon and Jewett, 1980). In many of these activities, besides being active participant or spectator, the physically challenged or handicapped person can serve as a committee member, judge or officiating official in any organized physically challenged sports competition or para-olympic sport fiesta.

\section{Values Of Recreation To The Physically Challenged}

Recreation is a distinct phase of human activity. It is characterized by the direct satisfaction which it brings to promote life. Recreation is beneficial and constructive to the individual, be you a 'handicap' or a 'normal' person. Adesanya (1987) regarded recreation as a means of reducing delinquency and crime. Most often, people with emotional disturbances involve themselves in different forms of delinquent behaviours and crime. However, engaging people in recreation helps to suppress these negative acts. It also helps to build, sustain and promote physical and mental health. Some beneficial effects of recreation include: strengthening the muscular system; increase circulation; greater respiratory activity; better elimination of waste and improved digestion; acts as a soother of troubled spirits and as a therapeutic agent for the mentally disturbed patients or as 'preventive medicine of the future' of the disabled (Agwubike, 1986, and Adesanya, 1987). According to Adam, etal (1975) asserts that there is no specific therapeutic drugs available (as yet) that will accelerate the normal healing of injured musculoskeletal tissues, or that will make a weak muscle stronger, a relax ligament tighter, a stiff joint mobile or a deformed bone straight. This, however, demands new approaches to take over medical care system. It is on this premises that medical and allied medical professionals are frequently requested to prescribe or advice their patients on exercise including therapeutic recreational activities, for the prevention or cure of disease as well as in the realization of the potentials for functioning in a dysfunctional individual. The effectiveness of this treatment is likely to depend on the nature of the recreational activity, the attitude of the respondent or handicapped towards the activity and the respondent's physiological and psychological state during the exercise (salmon, 1961).

Recreation is not a panacea to cure of disabilities but can act as an antidote to escalation of such conditions that may have subjected the handicapped to major surgery and long periods of stay in the hospital. This explains the need for bodily activity necessary for the physically challenged problems.

\section{Conclusion}

The need for bodily activity for the physically challenged cannot be under-estimated. It was formerly believed that recreational activities were not meant for people who are impaired. Modern education and scientific technological development has proved this assertion wrong with the provision of varied recreational activities with modifications and adaptations. Such activities are those of daily living, expensive and creative, intellectual and educational involving games and sports for a healthful living.

Recreation is beneficial and constructive to the individual. Participation in whole-some form of recreation contributes to physical, mental, emotional and social wellbeing of the individual. Recreation is not a curative antidote for all disease, but in its better form serves as a therapeutic measure, and aimed at producing change, leading from ill-health or dysfunction towards integrative function for one's life. A good programme of recreational activities promotes fitness, and fitness promotes health and health promotes the joy of living. Regular participation in recreational activities has an important role in maintaining, enhancing, restoring and 
invigorating health. Conclusively, properly planned programmes of recreation add years to a person's life and life to a person's years.

\section{Recommendations}

In view of the fact that the lives of the physically challenged or handicapped are so important to themselves, their families, societies and the nation at large, it is hereby recommended that:

1. Recreation education for the physically challenged should be advocated and given recognition in the total physical education programme.

2. A well planned programme of recreational activities should be provided in all phases, streams, arms or levels of our educational system for the promotion of health and fitness.

3. There should be a national body on recreational activities. This body should be charged with the responsibilities of planning and providing recreational programmes for the handicapped.

4. Properly equipped rehabilitation homes or centers should be build in each institution and public areas so that the physically challenged can constant themselves and be very friendly with each other in the participation that can promote a sound mind in a sound body.

5. There should be proper training and orientation of personnel that will handle the handicapped in varieties of recreational activities. This will pave way for the disabled when mentally fatigued from long concentrated office work, or studies should furnish their bodies with pleasurable activities that will refresh their body systems and restore their emotional vigour.

6. Government at all level (local, state or federal) should provide adequate recreational facilities and equipment with modifications to suit specific or each handicapped condition.

7. Schools, religious organizations, homes and other voluntary agencies should be encouraged to provide recreational activities for their subjects in one hand, and the physically challenged in particular. For it has a favourable influence upon lifespan. It also delays the onset of the stigmata of ageing process.

\section{Reference}

[1]. Adams, R.C; Daniel, A.N and Rullman, L (1975) Games, Sports and Exercises for the physically handicapped philadephia; Lea and Fabiger

[2]. Adesanya, O.A (1987) "provision of community recreation facilities as a surest approach to national awareness for recreation participation". The Jonapher, vol. 6, No. 1, P. \&-15.

[3]. Adima, E.E (1988) Fundamentals of special Education. Heinemann Educational Books (Nigeria) LTD, Ibadan.

[4]. Agwubike, C.O (1986) "Recreation: its Therapeutic Approach". Proceedings of the $16^{\text {th }}$ Annual conference of the NAPHER-SD, P. 27-37.

[5]. Butcher, C.A. (1975) Administration of Health and Physical Education Programmes including Athletics. St Louis, C.V Mosby company. P.597.

[6]. Butler, G.D. (1967) Introduction to community Recreation $\left(4^{\text {th }}\right.$ ed), New York, Mcgraw-Hill Book co.

[7]. Daniel, A.S (1965) Adapted physical education. Harper and Row Publishers, Inc New York; P.425-426.

[8]. Dunn, L.M (1980) exceptional children in the school: Special Education in Transition (2 $2^{\text {nd }}$ ed), New York; Rinchart and Winston company.

[9]. Faith, H.F (1978) special Education: Adapted, and corrective Development ( $4^{\text {th }}$ ed) philadephia W.B Saunders company.

[10]. Faye, J.D (1974) “Adapted Table-Tennis for wheel-chair multi-handicapped individuals". JOHPER vol. 45, P.81.

[11]. Gray, D.E and Greben, S. (1974) Future perspective, Park and Recreation. Calif state University, Long Beach, P.49.

[12]. Hyman, D. (1974) “Teaching the Blind student Archery Skills". JOHPER, 45, P. 46-49.

[13]. National policy on Education (1977) $2^{\text {nd }}$ Edition, Lagos, NERDC press.

[14]. National policy on Education (2004) $4^{\text {nd }}$ Edition, Lagos, NERDC press.

[15]. Nixon, J.E and Jewett, A.E (1980) An Introduction to physical Education $\left(9^{\text {th }}\right.$ ed) philadephia: saunder college press.

[16]. Okunrotifa, E.B (1980) "physical Recreation opportunities for the Handicapped children in Oyo and Ondo states, Nigeria". $10^{\text {th }}$ Annual proceedings of the NAPHER-SD, p.38-47.

[17]. Oluwoyo, G.O (1986) "Recreation:" A Fundamental and universal Human Need" proceedings of the $16^{\text {th }}$ Annual conference of the NAPHER-SD, P. 121-128

[18]. Omoruan, J.C (1977) "Recreation and Competitive sports". The JONAPHER, vol. 1, No. 1.

[19]. Oyerinde, O.O (1986) "Perspectives of Health and National unity in Indigenous Recreational Activities" proceedings of the $16^{\text {th }}$ Annual conference of the NAPHER-SD, P.53-56.

[20]. Salmon, C.A (1961) the New Health and Longevity, India, The oriental Watchman Publishing House, Salisbury park.

[21]. The Holy Bible (KJV) I Samuel: 16: 14-23

[22]. The Department of Education and Science (1971) Physical Education for the physically Handicapped. London.

[23]. Udenyi, A.E (1986) "Attitudes of the Handicapped Towards physical Education in Benue state" unpublished project Report, college of Education, Katsina-Ala.

[24]. William, C.C (1976) The need for Leisure Education for Handicapped Children and youth” JOPER, vol. 47, No.3, P. 53 -55. 